\title{
AS REFORMAS LEGAIS E O PROCESSO DE DESCENTRALIZAÇÃO: ASPECTOS JURÍDICOS E POLÍTICOS ${ }^{1}$
}

\author{
Fernanda Henrique Cupertino Alcântara
}

\begin{abstract}
RESUMO
O artigo discute a descentralização buscando conciliar o campo jurídico com o político, relatando as diferenças quanto à conceitualização e operacionalização do conceito nestas duas áreas do conhecimento. $A$ descentralização é apresentada como um fenômeno decorrente da descentralização, abrigando, com isso, as possibilidades de promover uma democratização da tomada de decisões ou um acirramento do controle político do "coronelismo" nas relações políticas. Objetiva demonstrar a relação existente entre o federalismo e a descentralização, partindo do pressuposto de que existem vários tipos de descentralização, os quais podem ou não ocorrer ao mesmo tempo. Além disso, discute a implementação das reformas que visaram instaurar a descentralização e seus resultados efetivos. Para efeito de conclusão, busca demonstrar que o processo de descentralização não é automático e as previsões legais não são naturalmente transformadas em práticas sociais.
\end{abstract}

PALAVRAS-CHAVE: descentralização; reformas legais; Direito Administrativo.

\section{INTRODUÇÃO}

A revisão histórica sobre como o município foi concebido pelo ordenamento jurídico brasileiro chega a um ponto analítico importante a partir da Constituição de 1946. Como é sabido, a Constituição de 1891, a Reforma Bernardes de 19251926, a Constituição de 1934 e a de 1946 asseguraram a autonomia municipal e precederam, com isso, o processo de descentralização que seria desenvolvido posteriormente ${ }^{2}$. Provavelmente, em razão disso, temos freqüentemente presenciado uma naturalização, por parte dos estudiosos, da relação causal entre municipalização e descentralização, entendendo que um fenômeno diretamente promove o outro de modo simultâ-

\footnotetext{
1 Este artigo resultou de parte da minha tese de doutorado em Sociologia defendida no Instituto Universitário de Pesquisas do Rio de Janeiro (Iuperj) em 2008.

2 No Brasil, as reformas dos anos 1930 com o Estado Novo, a reforma administrativa desencadeada pelo Decreto-Lei n. 200/67 e, mais contemporaneamente, a Reforma Gerencial de 1995, promovida pelo Ministério de Administração e Reforma do Estado (MARE) constituem-se nos três grandes marcos reformadores no contexto da administração pública federal.
}

neo, reforçando-se mutuamente. A descentralização observada na história política brasileira foi amplamente defendida pelos municipalistas, mas foi também acompanhada por uma vasta discussão acerca das funções e atribuições que cada unidade da federação deveria sustentar nesse novo momento histórico. Não é por acaso que a complexidade do projeto de descentralização brasileiro provavelmente decorre, entre outras coisas, das múltiplas e, por vezes, coincidentes competências, modelando um sistema de partilhas e estimulando a cooperação entre as unidades da federação. Souza (2001b) lembra que a redemocratização assistida em vários países no final do século passado foi acompanhada de "Constituições refundadoras" de uma nova ordem institucional e federativa, pautada na descentralização política e financeira, o que acarretou uma mudança no papel dos entes federativos. Além disso, a mudança é constitucional porque é necessário que a norma fundamental orientadora e limitadora de toda a pirâmide kelsiana, que representa nosso modelo de ordenamento jurídico, seja alterada para que se possa organizar e estruturar o novo estado. Souza (idem) demonstra que a Constituição de 1988 ao reconstruir o federalismo (que para ela é inerentemente acomodação de conflitos) gerou inú- 
meros embates, principalmente porque esse novo federalismo fundou-se na descentralização política e tributária, o que, segundo seu argumento, fortaleceu a democracia. Mas, como veremos adiante, a descentralização não leva necessariamente a contextos democráticos (ABRUCIO, 2005, p. 49).

\section{SIGNIFICADOS ATRIBUÍDOS À DESCEN- TRALIZAÇÃO}

À primeira vista parece que o termo "descentralização" possui sempre o mesmo significado e permite dúvidas. Porém, o conceito não é "lugar comum" na teoria social e, por isso mesmo, requer o detalhamento necessário. Como acusa a bibliografia referente (ARRETCHE, 1999; SOUZA, 2003a; 2003b; ALMEIDA, 2005), muitos equívocos ocorrem quanto à compreensão da diferença existente entre federalismo, descentralização e desconcentração. Por essa razão, adotarei uma distinção básica para os dois últimos conceitos, entendendo a descentralização como o processo no qual aos órgãos locais ou regionais é atribuída personalidade jurídica, patrimônio e estrutura de funcionamento particulares, sem que se crie novos órgãos na estrutura administrativa (BANDEIRA DE MELLO, 2008). Claramente, esse recorte conceitual utiliza elementos do ponto de vista jurídico. Em outras palavras, equivale a dizer que a descentralização consiste na criação de uma nova pessoa jurídica para cuidar de uma função específica da administração pública. Por outro lado, para a Ciência Política, descentralizar é repassar atribuições de um órgão diretivo central a órgãos locais, considerando-se que, para tanto, necessariamente ocorre transferência de poder político, administrativo e/ou fiscal do poder central para os governos subnacionais (GSN) (SOUZA, 1998; 2001b; ABRUCIO, 2005). Não bastasse essa diferenciação quanto ao conceito de descentralização, existe outro conceito relevante que contribui para a complexidade dessa questão, qual seja, o de "desconcentração". Note-se bem que enquanto o primeiro supõe autonomia, o segundo declara submissão.

A desconcentração, do ponto de vista jurídico, mantém uma hierarquização entre órgãos centrais e locais, ou seja, a função é atribuída a um órgão cuja responsabilidade é da pessoa jurídica ao qual aquele se submete na hierarquia da administração pública (BANDEIRA DE MELLO, 2008). Percebe-se, portanto, que a concepção da Ciência Política contempla tanto o que o Direito chama de descentralização quanto de desconcentração, em uma mesma perspectiva.

Independentemente de qual interpretação seja adotada, parece incontestável que, em princípio, tanto a descentralização quanto a desconcentração constituem-se como recursos utilizados na tentativa de democratizar-se um regime político, possibilitando a existência de uma maior participação popular e valorização das localidades. O que as diferencia sobremaneira é a capacidade de autonomia, e o que as une é a oposição à centralização. Veremos, contudo, que essa é apenas uma das perspectivas possíveis, embora não seja nada nova. Considerando-se a relação dialética dos fenômenos sociais, pode-se afirmar que tanto os fenômenos "centralizadores" quanto os "descentralizadores" podem implicar o interesse pela concentração de poder direta ou indiretamente, ainda quando alcançado por meio da concessão de autoridade e tomada de decisão sobre assuntos de interesse da população. Paradoxalmente, em um período democrático, podese utilizar os mecanismos de centralização para concentrar a tomada de decisão e os de descentralização para aumentar a ramificação do poder e angariar apoio em outros níveis políticos. Tendo em vista este cenário, precisamos nomear os prós e contras do então inevitável movimento de descentralização.

Atribuir mais responsabilidade ao município autonomiza-o quanto à "boa vontade" de seus apoiadores em outras esferas, como deputados, senadores, governadores e até mesmo o Presidente da República, mas legitima e autoriza, no momento em que também viabiliza, sua atuação em novas áreas que antes não constavam no rol de atribuições dos administradores municipais. Não implica dizer que os favores políticos e a necessidade de representação em outras esferas cessem de existir, mas os arranjos e pactos construídos deixam de ter um caráter de subordinação e dependência extremada de empenho particular de administradores locais para com outros níveis da federação. Em outras palavras, entende-se que o movimento de municipalização aproxima-se consideravelmente também da descentralização, em termos jurídicos. A descentralização permitiu também uma proximidade do eleitorado com o poder Executivo municipal, na medida em que garantiu àquele mecanismos de participação e fiscalização 
efetivos. Diga-se de passagem, muitos autores elegem essa como a principal e mais importante característica do fenômeno da descentralização (cf. LORDELLO DE MELLO, 2004). Mesmo assim, Lubambo (2006) ressalta que existem alguns fatores específicos que determinam a aprovação popular da gestão pública, os quais sofreram grande influência do processo de descentralização e podem desencadear efeitos maléficos para a administração pública, na medida em que esta, em função da abertura à participação, veja-se obrigada a cumprir interesses de determinados grupos ou pessoas que se utilizam da manipulação e convencimento dos cidadãos para torná-los ignorantes acerca do que é o interesse público. Expõe também o debate entre aqueles que entendem o governo local como propulsor e representativo da democracia e aqueles que acreditam ser este o contexto propício para o desenvolvimento de maneiras clientelistas e ineficientes de administração pública. Essas características resumem de modo claro o debate instaurado em torno desta problemática.

Em sintonia com as menções anteriores, Sarmento (2005) lembra que a ênfase na descentralização levou à política de municipalização na década de 1990, que atingiu diversos setores, inclusive a educação. Esse processo estava ligado à redemocratização do país, à ampliação da participação popular e do poder local. Novamente, instala-se o paradoxo entre os efeitos possíveis da descentralização. Embora o autor não cite, por exemplo, que juntamente com a municipalização do ensino, que retirou dos estados vultuosas responsabilidades financeiras e administrativas sobre inúmeros estabelecimentos de ensino, ocorreu uma "partidarização" dos representantes concorrentes aos cargos de diretores escolares com participação direta dos políticos locais, no sentido de garantirem a seus aliados a ocupação destes postos. Desta forma, nota-se uma politização com participação às avessas. Talvez por razões semelhantes, Souza (2002) argumenta que a participação é vista como resultado da descentralização, mas que esse fenômeno não é tão simples e automático como se imagina, podendo configurar-se principalmente de duas formas, quais sejam, o empowerment ("empoderamento") e o "poder de voz" (liberdade para atuar nas esferas decisórias), sendo a última insistentemente adotada no Brasil, tendo materializado-se na forma dos Conselhos como requisitos de políticas públicas e ampliação do poder de escolha e veto. Contudo, não implica dizer que, em face da descentralização, os indivíduos necessariamente tornar-se-ão beneficiados pelo "empoderamento" e a efetiva participação em instâncias decisórias, ou mesmo que irá ser ampliada a participação de um modo geral - ainda que a descentralização promova o aumento da participação. Ao falar sobre os Conselhos Municipais, Souza argumenta: "A constituição desses conselhos decorre, em geral, de exigências da legislação federal. O papel dos conselheiros é tomar parte na gestão do programa, ou seja, fiscalizar a implementação de políticas decididas em outras esferas, alocar parcela dos recursos e acompanhar sua aplicação e os rumos da política pública. Para cada política social, é requerida a constituição de um conselho, em que os representantes da comunidade/usuários têm assento" (SOUZA, 2004, p. 38).

Nesse caso específico trata-se de uma previsão legal que garante o aumento da participação da população na tomada de decisão e fiscalização do emprego dos recursos públicos, mas não necessariamente é garantia de uma participação efetiva pautada no "empoderamento" e no "poder de voz". O dilema entre a previsão legal e a concretização da prática está presente em vários fenômenos e fatos citados anteriormente. Lógico que os Conselhos aos quais a autora refere-se ainda não foram devidamente estudados em seus processos e conseqüências, além de poderem resultar apenas de uma obrigação formal instituída pelas políticas públicas e serem acometidos por casos de corrupção e denúncias de submissão ao poder Executivo local, não alcançando, assim, os objetivos para os quais foram constituídos (SOUZA, 2002). Desse modo, mesmo que a Constituição de 1988 tenha instituído uma nova forma de fiscalização da administração pública local, por meio dos Conselhos Municipais, condicionandose cada programa de repasse de verbas federais para municípios à existência de um respectivo Conselho (por exemplo, Conselho de Merenda Escolar, Saúde, Educação e Bolsa Família), a Controladoria Geral da União (CGU) tem questionado a eficiência de tais mecanismos. Os motivos apontados vão desde o fato de os indivíduos que ocupam cargos comissionados dentro das Prefeituras Municipais (PMs) participarem e até mesmo presidirem tais colegiados, até a baixa partici- 
pação e representatividade dos usuários do serviço e de técnicos da área ${ }^{3}$.

Em suma, tomando-se a questão apenas como ilustrativa de um tema maior, a bibliografia que trata do assunto prevê dois pontos positivos para além da descentralização pura e simples: primeiro tem-se a questão da flexibilidade, que permitiria um melhor desempenho dos projetos locais por possibilitar que sua formulação fosse realizada de acordo com a realidade e características locais; segundo, a necessidade de criação de maneiras garantidoras e promotoras da participação popular, aqui entendida como composta por "[...] organizações sociais, formais e informais, que constitui o 'tecido associativo' empiricamente existente em um dado contexto" (SILVA, 2006, p. 156). Silva argumenta que existem muitos resultados possíveis para a relação entre a sociedade civil e a consolidação da democracia. Bastante ilustrativo desta afirmação é o exemplo inusitado que o autor fornece. Segundo ele, nos municípios de Gravataí e Sapucaia do Sul (RS), de 1997 a 2000, a sociedade civil organizou-se para impedir a democratização das respectivas gestões públicas municipais. Mesmo diante dessa realidade, ele considera que a participação social pode romper com as relações hierárquicas e clientelistas (idem).

Mas existem perspectivas não unidimensionais sobre esse assunto. É o caso de Coraggio, como podemos observar com a citação a seguir: "Por el lado político-administrativo, el proceso de reforma del estados que acompaña la reestructuración del mercado impulsa una transferencia de poder desde las instancias nacionales de gobierno, al menos formalmente democráticas, hacia, por un lado, instancias publicas de menor rango (Províncias, Municípios, comarcas) - las que para algunos son el mundo del clientelismo, el caciquismo y el sojuzgamiento personal, para otros el mundo de una democracia participativa posible - y, por el outro, hacia instancias supranacionales sin fundamento democrático ni responsabilidad ante los pueblos (accountability), como las tecnocracias de las asociaciones de comercio en bloques regionales o los organismos internacionales de financiamento o regulación del comercio. Finalmente, hay uma transferencia de funciones publicas, por un lado hacia grandes empre-

\footnotetext{
3 Ver, a respeito, o Jornal do Senado.
}

sas financieras, productivas, comerciales o mediáticas de âmbito nacional y global, por el outro hacia la 'sociedad civil' y de la variedad de organizaciones no gubernamentales, asociaciones voluntárias, etc. que la integran (incluso esta esfera registra la creciente actividad) de organizaciones no gubernamentales y movimientos de orden global" (CORAGGIO, 2001, p. 253).

Conclui-se, então, que a descentralização também pode produzir um resultado oposto do inicialmente pretendido, restando verificar qual é seu significado para o público diretamente atingido e em sentido mais amplo. Sobre esse assunto é importante problematizar não só a efetividade da participação e seus resultados, como também a própria relação entre (re)democratização e a ação da sociedade civil organizada. Neste contexto, existem vários elementos que são produtos diretos da descentralização administrativa, presente da década de 1970 em diante, tais como: orçamento participativo, conselhos setoriais, planejamento estratégico, fóruns, conferências e audiências públicas, os quais acabaram por contribuir, ao menos em tese, para a prática democrática.

Neste sentido, na medida em que vários organismos de financiamento já recomendavam o incentivo à participação popular em questões relativas a governos locais e para facilitar a implementação de políticas públicas, pouco tempo depois, na década de 1990 , já haviam se institucionalizado programas de acompanhamento de políticas públicas e orçamentos participativos (OP) no Brasil, independentemente de resultarem de iniciativa dos administradores locais ou de constituírem uma exigência legal (LIMA \& MOURA, 2005). Não obstante, vários problemas são apontados mesmo por esses autores que entendem haver uma correlação direta entre descentralização e democratização, podendo trazer à baila a própria questão da eficácia. "Não se desconhece, por outro lado, que a ênfase no poder local tem contribuído para justificar políticas neoliberais de desoneração do Estado central e para manter as práticas clientelistas, ainda muito presentes na cultura brasileira. Todavia, procura-se analisar como as experiências de participação e autonomia podem contribuir para ampliar a democratização e as soluções dos problemas sociais. $\mathrm{Na}$ área da educação e da saúde há um reconhecimento da necessidade de políticas integradas ao governo central" (SARMENTO, 2005, p. 1380) 
Souza (2004) argumenta que municipalizar é transformar os municípios em provedores de serviços, o que ocasiona um sistema de governança local, ao mesmo tempo em que inaugura uma nova institucionalidade. Para essa visão, a descentralização é basicamente uma questão política. $\mathrm{O}$ fato de o município acumular competências concorrentes ou comuns com os demais entes da federação diz muito acerca de como a relação intergovernamental deve constituir-se para alcançar um mínimo de eficiência ${ }^{4}$. A autora entende que, diante da diversidade de características próprias aos municípios brasileiros, tem-se uma grande dificuldade em estabelecer um perfil tipológico sobre a gestão local e a implementação de políticas públicas. Mas, apesar disso, acredita que a descentralização é condicionada mais pelo desenho institucional da política (incluindo "fatores de ordem gerencial"), do que por renda ou imposições constitucionais. Por exemplo, o estímulo à adesão por meio da distribuição de sanções e recompensas, como é o caso das políticas públicas de saúde e educação.

Voltando à questão dos significados da descentralização, de acordo com Souza (idem), não basta transferir a responsabilidade pela implementação, sendo necessário aproveitar a descentralização para envolver a população local, dando-lhe "poder de voz", "empoderamento" e "accountability". Torres e Marques (2004, p. 31) também argumentam que os mecanismos de participação geram accountability, que pode ajudar, por exemplo, a solucionar o clientelismo nos processos de seleção de beneficiários dos programas de distribuição de renda. Agem, portanto, diante

4 São competências partilhadas entre União, estados e municípios: assistência e saúde pública; assistência aos portadores de deficiência; preservação do patrimônio histórico, artístico e cultural; proteção do meio ambiente e dos recursos naturais; cultura, educação e ciência; preservação das florestas, da fauna e da flora; agricultura e abastecimento alimentar; habitação e saneamento; combate à pobreza e aos fatores de marginalização social; exploração das atividades hídricas e minerais; segurança do trânsito; políticas para pequenas empresas; turismo e lazer (SOUZA, 2004, p. 30). Em alguns setores ocorre um "vazio governamental", em outros pode-se observar um nível elevado de eficácia. Para Garson e Araújo (2001) a municipalização do ensino e da saúde, por exemplo, provocaram maior eficácia do gasto público, já que os serviços prestados foram expandidos, sem incorrer em uma elevação proporcional dos gastos. da constatação de que as PM(s) estão mais próximas da população, mas também são mais vulneráveis a fraudes. Esta é uma constatação da CGU, publicada no Jornal do Senado (PARA CONTROLADORIA, 2006), de acordo com a qual 2/3 dos municípios brasileiros sofrem com a má gestão. Esse diagnóstico não se restringe apenas ao "desvio de finalidade no emprego do dinheiro público", mas, principalmente às licitações e execução de obras. Por outro lado, a Confederação Nacional dos Municípios (CNM) argumenta que nem sempre o desvio de aplicação da verba quanto à finalidade constitui "desvio de dinheiro" ou ineficiência, podendo até mesmo demonstrar a busca da eficiência da gestão. Esses são apenas alguns exemplos, mas não constituem o âmago da problemática posta neste artigo.

Em outra obra, Souza (2001a) entende que, como a redemocratização e a descentralização caminharam juntas no Brasil, esta última pode favorecer a participação e o acesso aos centros de decisão, mas nem sempre é compatível com determinados tipos de políticas públicas, como as sociais, por exemplo. Presenciamos, portanto, uma agenda de construção e reconstrução de instituições democráticas, buscando participação e transparência, intimamente relacionadas à descentralização política e financeira dos GSN. Uma indicação importante é que a participação e a democratização da tomada de decisão presentes em algumas políticas públicas, ainda que não ocorra a continuidade destas últimas, lega ao públicoalvo e aos próprios administradores uma referência de prática associativa e de representação de interesses, os quais possuem vínculo causal imediato com outros projetos que contenham as mesmas características. É o caso, por exemplo, da herança que o orçamento participativo deixou para a população de Belo Horizonte e Porto Alegre ${ }^{5}$. Tomando-se o suposto de que uma política públi-

5 As pré-condições são, inclusive, indicadas como elementos impeditivos da implantação do Orçamento Participativo (OP) em cidades com características diferentes de Porto Alegre. O OP gera práticas participativas e, com isso, fortalece a democracia. Mas o conceito de OP pode ser visto por vários ângulos, principalmente do ponto de vista da gestão, da educação, da política e do comportamento social. Por exemplo, Dias (2000) argumenta que o OP também pode ser um projeto do poder Executivo para controlar o poder Legislativo, a partir da manipulação, em um sentido amplo, do poder de pressão da população. De qualquer 
ca derivada do movimento de descentralização e caracteristicamente fundada na participação popular facilita a implantação de outros projetos que possuam um caráter semelhante, é importante notar que este é apenas um dos fatores que condicionam o aumento do número de iniciativas nesse sentido. Outro fator que contribuiu para essa prática foi o aumento das receitas municipais, o que permitiu a expansão de políticas fundadas em mecanismos de participação popular. E um terceiro fator seria o crescimento da representatividade dos partidos de esquerda em administrações públicas, que comumente defendiam a participação como um compromisso eleitoral. Nesse sentido, participar não é apenas influenciar as decisões, como pensam os organismos multilaterais, mas também efetivamente decidir.

Todos os argumentos apresentados neste tópico como resultado da leitura de estudiosos do tema são corroborados por este artigo, mesmo os aparentemente contraditórios. A descentralização não é apenas repasse de poder do centro para o GSN; envolve também vários elementos complexos que atingem, inclusive, as políticas públicas. Descentralizar também não implica necessariamente um aumento da participação popular e do "capital social", podendo incorrer em aumento do "coronelismo", requerendo, para impedir tal fato, um maior controle e normatização por parte dos organismos centrais ${ }^{6}$, além de uma efetiva promoção da participação para a obtenção de práticas de accountability.

Dentre os defensores da descentralização destaca-se Tavares Bastos, que já em 1870 alertava para a necessidade de adotar-se um regime federativo para que o Brasil alcançasse a descentralização. Em decorrência, ele previa que os recursos chegariam às localidades, passando antes pela gestão das províncias. Sem tais mudanças o autor acreditava

modo, independentemente do conceito e ângulo adotados, o OP tem confirmado-se como um importante mecanismo de estímulo à mudança do comportamento social, ao promover a capacitação, informação, associativismo e diálogo diferenciado entre o poder público e a sociedade organizada. O argumento é que o "empoderamento" da população mais pobre ganha relevo se comparado aos ganhos materiais obtidos, embora tenha aumentado o acesso à infraestrutura e ao investimento público em setores até então negligenciados pela administração pública, podendo reduzir, dessa forma, o clientelismo.

6 Ver também Lima e Moura (2005). ser difícil que o país alcançasse um nível de desenvolvimento econômico e social adequados. Esse pensamento também foi expresso por Lordello de Mello, um século mais tarde, e, contemporaneamente, Souza (2001b) coaduna com a interpretação acerca das implicações desses diagnósticos, mas ressalta que o federalismo também pode ser centralizado, sendo a descentralização apenas uma característica, como vimos anteriormente. A dissociação conceitual entre federalismo e descentralização inicia-se a partir desse pressuposto, ao qual mais tarde retornaremos.

Segundo Lordello de Mello (2004), um dos maiores entraves ao desenvolvimento brasileiro encontrava-se à sua época na ausência de uma definição para o papel do município na estrutura administrativa brasileira. Isso se refletia tanto no acúmulo de todas as funções relativas à esfera pública, na coincidência de responsabilidades (fazendo que acontecesse uma concorrência entre municípios e estados), e em um desarranjo quanto à exploração devida das fontes de receita. Além da crítica referente às funções acumuladas pelos municípios brasileiros, esse autor também ressalta as implicações da falta de qualificação técnica do funcionalismo público e de assessoria técnica interna à administração pública ${ }^{7}$. De acordo com ele, para fazer frente a tais problemas caberia um esforço no sentido de promover a descentralização, não só jurídico-administrativa, como também no que tange ao papel dos municípios, isto é, alcançar a autonomia política; mesmo diante da constatação de que os municípios brasileiros desfrutam de uma autonomia considerável no que diz respeito à elaboração de leis, controle do orçamento municipal, arrecadação de impostos e tributação. Para viabilizar essa necessidade, caberia à União estabelecer o papel do município, suas competências e as formas de prestação de contas correspondentes, ao mesmo tempo em que modificaria nosso ordenamento jurídico para conferilo o status de ente da federação e sua autonomia.

\section{TIPOS DE DESCENTRALIZAÇÃO}

Tratamos do conceito e de alguns de seus notáveis defensores, restando agora apontar os tipos mais comuns de descentralização. Rodden

\footnotetext{
7 Tal constatação justificou, entre outras coisas, a criação do Instituto Brasileiro de Administração Municipal (IBAM), do qual Lordello de Mello foi um dos fundadores.
} 
(2005) afirma que, embora a literatura trate a descentralização como uma transferência de autoridade do centro para os governos subnacionais, este conceito é mais complexo do que a teoria foi capaz de vislumbrar. Para ele, a descentralização não possui um formato único, ainda que considerada um fenômeno mundial, e pode ser de três tipos não excludentes: fiscal, política e de politicas. Para o autor, ao contrário do que a teoria clássica diz, descentralização não implica necessariamente autonomia, no sentido de independência para os governos subnacionais, no que tange à gestão fiscal, à política e à gestão de políticas. Ele incorpora, então, um argumento novo ao dissociar descentralização de "autonomia local". A crítica de Rodden centra-se no argumento de que os autores que tratam desse assunto, especificamente a descentralização fiscal, concentramse na distribuição das receitas e despesas entre os entes da federação, negligenciando outras questões. Adverte, ainda, que não importa apenas a quantidade de receita e concentração, mas também a "estrutura regulatória das finanças subnacionais"; em outras palavras, é importante considerar a fonte da receita que sustenta os gastos descentralizados. Comparativamente, o grau de descentralização varia em função dos instrumentos utilizados para medir a autonomia frente questões específicas: 1) a capacidade fiscal é condicionada tanto pela receita própria, pelas transferências, quanto pela possibilidade de endividamento público, o que pode incorrer em autonomia subnacional ou na sua negação. Em linhas gerais, seu argumento é que os dados empíricos não demonstram uma transferência de poder, mas sim uma prevalência de autoridade compartilhada; 2) quanto à descentralização política, poder-se-ia verificá-la por meio das formas como as eleições regionais e locais ocorrem. Por exemplo, o voto popular caracteriza um processo descentralizado.

Contrariando essa postura, outros autores ignoram a existência de diversos tipos de descentralização, ou, ao menos, não se colocam o mesmo problema. É o caso de Almeida (2005), por exemplo. Contudo, parece muito mais plausível falar em tipos distintos de descentralização conforme a área sobre a qual ela incide. Utilizando essa diferenciação em um sentido avançado, Falleti (2006) afirma que a ordem de implantação das reformas descentralizadoras interfere no resultado final das mesmas. Os resultados obtidos "dependem da seqüência em que diferentes tipos de reformas políticas descentralizadoras (administrativa, fiscal e política) acontecem" (idem, p. 47), o que constitui a teoria seqüencial da descentralização, que valoriza questões de contexto e de médio prazo, pautando-se em três premissas: 1) a descentralização não é um processo unidimensional de políticas públicas, mas tridimensional; 2) é necessário considerar os "interesses territoriais" dos políticos; 3 ) deve-se considerar as conseqüências de uma seqüência de projetos descentralizadores para a relação entre os governos. O processo é tridimensional porque se compõe das reformas fiscal (quanto à arrecadação e alocação), administrativa (quanto à administração dos serviços sociais, por exemplo, autoridade para formular políticas) e política (quanto à forma de indicação para cargos eletivos e representação territorial dos interesses).

Em suma, a teoria seqüencial entende que a descentralização é "um processo de reformas das políticas estatais" (idem, p. 60), que leva em consideração os interesses territoriais de políticos nacionais e subnacionais e a seqüência das políticas descentralizadoras (administrativa, fiscal e política). Para a autora, como a descentralização buscou reformar o estado pós-desenvolvimentista, dando origem a "um estado orientado para o mercado (ou neoliberal)" (ibidem), seu fundamento não pode ser dissociado desse contexto. Sendo assim, a descentralização administrativa transfere a administração dos serviços sociais, podendo ser ou não autofinanciada. A descentralização fiscal estabelece políticas para ampliar as receitas dos GSN e, com isso, aumentar sua capacidade fiscal. No caso brasileiro, a descentralização fiscal pautou-se na transferência de recursos, mas ela também pode ocorrer por meio da criação de impostos cobrados pelos GSN ou a delegação a eles para a cobrança de impostos federais. A descentralização política permite aos GSN o acesso aos centros de decisão, ao mesmo tempo em que fornece à população mecanismos de representação e de atuação direta.

A teoria seqüencial da descentralização prevê que a ordem das reformas condiciona o resultado total e o de cada reforma separadamente, bem como afeta as relações intergovernamentais. A ordem interfere porque a primeira reforma impõe constrangimentos e incentivos às demais, podendo ou não criar "mecanismos de auto-reforço" entre os estágios do processo. Isso depende de 
quais interesses prevalecem: 1) se forem os interesses nacionais, a seqüência lógica seria descentralização administrativa, fiscal e política; 2) se os interesses subnacionais, a seqüência seria descentralização política, fiscal e administrativa ${ }^{8}$.

A relação entre a descentralização e os tipos de estados não pode ser negligenciada, bem como os tipos de regime e de governo que ela engendra ou condiciona. Entretanto, tal discussão não cabe no recorte exíguo que sustenta este trabalho. Principalmente, em razão do espaço disponível.

\section{FEDERALISMO E DESCENTRALIZAÇÃO}

Assentado o conceito de descentralização, deve-se correlacioná-lo ao modelo federalista. Em linhas gerais, o federalismo "não é uma distribuição particular de autoridade entre governos, mas sim um processo - estruturado por um conjunto de instituições - por meio do qual a autoridade é distribuída e redistribuída" (RODDEN, 2006, p. 17), sendo tal processo legitimado por uma espécie de "contrato federal", comumente chamado por nós de "pacto federativo", responsável por determinar as "regras do jogo" para a relação entre a União e os governos subnacionais. O federalismo tem por base "a representação dos estados na elaboração de políticas do governo central", atuando como veto players, e, para tanto, estabelece-se uma relação intergovernamental bastante complexa.

Desse modo, federalismo não equivale à divisão de tarefas, nem tampouco significa ausência de governo central em assuntos não-nacionais. Fundamentalmente também não implica ausência de intervenção, visto que, ao cederem a sua soberania para a construção de um estado maior e mais forte, cada estado-federado submete-se às vontades da nova entidade criada. O que ocorre é uma relação de interdependência, na qual a União assume a dependência para com os governos subnacionais na medida em que precisa dos estados para implementar suas ações, inclusive normativas, já que estes funcionam como veto players. Por outro lado, os GSN dependem da União como gestora e agregadora. Assim, a descentralização, ao contrário do que comumente

\footnotetext{
8 Para Falleti (2006), o Brasil seguiu esta última seqüência, o mesmo tendo ocorrido, por exemplo, na Colômbia, o que garantiu autonomia significativa a governadores e prefeitos, enquanto a Argentina seguiu a primeira alternativa.
}

se afirma, pode aumentar a corrupção por dificultar a prestação de contas, ao criar "camadas de governo" que interpõem uma "responsabilidade compartilhada". Além disso, a "superposição de autoridade" ou a "autoridade regulatória" não seriam compatíveis com a descentralização de fato, embora ocorra recorrentemente em projetos dessa natureza.

Souza (2003b, p. 142) lembra também que federalismo e descentralização são coisas distintas, sendo que o primeiro pauta-se, basicamente, em dois pilares: "desenho constitucional e partilha do poder territorial”. Em outra obra, Souza (1998) reitera o fato de que, no caso brasileiro, a Constituição de 1988 promoveu tanto uma descentralização dos recursos quanto uma descentralização política. Relacionando esses conceitos ao de federalismo, a autora conclui que os primeiros são parte da discussão relativa ao último. Mas, sobretudo, adverte que o federalismo não precisa da descentralização e tampouco depende dela, podendo existir em outra circunstância. Não obstante, não se ignora o fato de que, ao juntarmos federalismo e descentralização, tem-se um sistema institucional bastante distinto. Sendo assim, em cada país o federalismo consolida-se por meio de arranjos diferentes, mas fundamentalmente, para a autora, o federalismo é uma ideologia ou, melhor dizendo, "[...] uma forma de acomodação das demandas de elites com objetivos conflitantes, bem como um meio para amortecer as enormes disparidades regionais" (idem, p. 3). Desse modo, o federalismo trata a questão da desigualdade entre as regiões, quando fornece maior representatividade política às regiões mais pobres, como o Nordeste, por exemplo, ou com o sistema de arrecadação e distribuição de receitas determinado em função das diferenças quanto à receita própria.

No caso brasileiro, tanto a descentralização quanto o federalismo conseguiram acomodar as diferenças regionais (ibidem). Mas, de acordo com Souza (2001b), na promoção da descentralização no Brasil não houve a preocupação com a formulação e implementação de políticas públicas, preocupando-se apenas em atender às demandas locais. Simultaneamente, houve a diminuição dos recursos fiscais federais, mas no momento seguinte à consolidação da descentralização o governo recentralizou os recursos fiscais em nome da política macroeconômica. É uma questão interessante, 
recuperada pela autora em Souza (2003b), ao demonstrar que os municípios foram compatíveis com o projeto de descentralização, mas as regiões metropolitanas (RMs) não o foram porque resultaram da Lei Complementar n. 14/73, produto do período militar.

Para Souza (2003a) a federação é marcada pelas desigualdades regionais e pelas disputas por recursos federais. Essas tensões são reguladas por normas formais e informais. Mesmo com a descentralização dos recursos federais, a partir da Constituição de 1988, os GSN permaneceram pressionando o governo para que pudessem obter recursos, principalmente por meio das emendas ao orçamento federal. Reafirma, portanto, a noção de que coexistem, para a Comissão de Orçamento, que é o caso estudado por ela, "regras distributivas formais (constitucionais) e informais (negociadas caso a caso)" (SOUZA, 2003a). As regras informais buscariam sanar a dificuldade em alcançar-se a equalização fiscal com as regras formais, sendo que as emendas ao orçamento refletem o resultado das disputas informais, entre regiões desiguais, por recursos da União.

A descentralização fiscal fornece, então, os recursos, podendo garantir reserva legal para os seus gastos, estabelecendo regras constitucionais que determinem a adesão às políticas públicas formuladas pelo governo federal. Sabe-se, contudo, que interfere nesse processo o legado das políticas prévias, os custos financeiros e políticos, o desenho do programa de municipalização, os atributos institucionais da política, entre outros. Para Arretche (1999), a atuação dos níveis mais abrangentes de governo (União e estados) sobre os municípios, estimulando a adesão aos programas de descentralização, é mais importante do que características como porte da renda per capita ou do Produto Interno Bruto (PIB), tamanho do município, índice de participação política e taxa de associativismo. O estado interfere principalmente fornecendo capacitação municipal e utilizando sua burocracia para agir favoravelmente a esse processo. Neste sentido, a "ação do Executivo estadual" no processo de municipalização das políticas públicas é tanto uma variável dependente como independente para avaliar a adesão e os incentivos frente às estratégias de indução. Essas estratégias devem conter disposição e meios para implementar as políticas públicas, isto é, recursos financeiros, políticos e administrativos.
Complementando essa visão, Souza (2002) demonstra que os municípios não alcançaram autonomia financeira, visto que ainda dependem de transferências de recursos, e a política de controle fiscal cerceia esse acesso. Alguns municípios são incapazes de arrecadar recursos próprios, tanto pela inexistência de atividade financeira quanto pela pobreza ${ }^{9}$. Por essa razão, é importante atentar para as relações intergovernamentais. Segundo a autora, o conceito de descentralização é vago e confuso, acentuando o fato de que a literatura da área costuma ignorar os governos intermediários, como os estados. Em todo caso, talvez o dado mais relevante sobre as conseqüências da descentralização é que ela auxilia na formação de capital social, como já mencionado anteriormente. Contudo, os resultados da descentralização são altamente diferenciados, devido à "natureza" da mesma, sendo que as políticas públicas são influenciadas não apenas pelo conteúdo, abrangência e aspectos estruturais como também pelo processo "de recepção" das mesmas, largamente determinado pelas características locais. A visão de Souza (idem) oferece um contraponto aos estudos que consideram a política pública ensimesmada, ignorando as externalidades que constroem e modificam suas estruturas.

Frente ao dilema das relações intergovernamentais e da autonomia relativa às subunidades, Abrucio (2005) também ressalta a importância da coordenação intergovernamental, a qual diz respeito às formas de integração, compartilhamento e decisão entre os entes da federação. De acordo com o autor, o Brasil enfrenta dilemas de coordenação intergovernamental, determinados por "especificidades históricas", "coalizões sociais" e "arranjos institucionais". Essa interpretação pauta-se na premissa de que o federalismo dá conta de uma situação de heterogeneidades e, por isso, visa manter a unidade territorial, mesmo diante da diversidade. Como resultado, tem-se um pacto federativo, que implica tanto em autonomia e poder quanto em interdependência. Por isso, para Abrucio, a descentralização constitui-se em um mecanismo importante para impedir a concentração de poder. A interdependência entre unidades políticas autônomas gera "processos decisórios compartilhados" (idem), sendo assim, para obter-se uma coordenação federativa dever-se-ia combinar competição e cooperação. Contribui, 9 Arretche e Marques (2002) citam também a "preguiça
fiscal" dos municípios de pequeno porte. 
portanto, para a criação do que ele denominou "redes federativas", nas quais os entes da federação participariam dos processos decisórios, contrapondo-se ao "federalismo estadualista" ou "modelo unionista autoritário". O "federalismo estadualista e predatório" resultaria do fortalecimento dos governos estaduais, tanto política quanto financeiramente, acrescido da competição não cooperativa entre os estados e deles com o governo federal, tendo como exemplos marcantes a guerra fiscal e o elevado endividamento público. Outro exemplo é o que ele denomina de "prefeiturização" ou "municipalismo autárquico", correspondente à crença de que os governos locais conseguem resolver sozinhos seus problemas de ação coletiva, negligenciando-se a importância da cooperação e da formação de consórcios, para tanto ${ }^{10}$.

O chamado federalismo estadualista enfraqueceu com o pacote de medidas atrelado ao Plano Real, ao qual Abrucio (2005) denomina a "Era do Real", principalmente devido aos planos de ajuste fiscal e estabilização monetária. Além do mais, o Plano Real, ao elevar as taxas de juros, aumentou as dívidas dos estados, fazendo que os bancos estaduais entrassem em crise. $\mathrm{O}$ autor credita a responsabilidade da crise, no entanto, aos governadores que mantinham um gasto excessivo com pessoal e previdência pública. De todo modo, a coordenação estabelecida nos governos Fernando Henrique Cardoso (FHC) impedia que seus mecanismos fortalecessem os estados, sendo eles: estabilização monetária; reformulação do estado e modernização da estrutura fazendária (controle do deficit público e metas fiscais); repasse de recursos condicionados à participação e fiscalização do governo local, por meio dos conselhos de políticas públicas; aprovação de leis ou emendas constitucionais para coordenar as relações intergovernamentais; coordenação nacional de políticas sociais; criação de políticas (de geração) de renda sob a responsabilidade do governo federal; criação de instrumentos de avaliação das políticas descentralizadas. A Lei de Responsabilidade Fiscal (LRF) é um exemplo de mecanismo de coordenação federativa, pois, entre outras coisas, instituiu mecanismos de restrição orçamentária ${ }^{11}$.

\footnotetext{
10 Abrucio (2005) lembra que na área de saúde os consórcios são mais comuns. Ver também Souza (2004).

11 Garson e Araújo (2001) argumentam que a LRF é uma aliada do processo de municipalização, na medida em que regula os gastos e "determina" a receita.
}

Mas esse tipo de coordenação também depende diretamente da capacidade de que dispõe a burocracia federal, tanto para fiscalizar quanto para qualificar as burocracias subnacionais ${ }^{12}$.

\section{HISTÓRICO DA DESCENTRALIZAÇÃO E DAMUNICIPALIZAÇÃO}

Se pudéssemos traçar um histórico da descentralização concretizada na criação de municípios e na municipalização, veremos Lordello de Mello apontando que apenas em 1938 observou-se o início da modernização da administração pública brasileira, com a criação do Departamento Administrativo do Serviço Público (DASP) ${ }^{13}$ e, com isso, o estreitamento das relações entre o município e a União. A descentralização administrativa, propriamente dita, só foi implantada, no entanto, com a Constituição de 1988, após um período de ditadura no qual a centralização política, fiscal e administrativa foram fortemente reforçadas. As reformas fiscais permitiram uma redistribuição da receita federal para os estados e municípios, o aumento da sua participação e conseqüente responsabilidade com relação às políticas públicas em todos os setores, principalmente com aquelas ligadas ao desenvolvimento local e à geração de renda. É crucial assinalar que, pela primeira vez na história da Constituição Brasileira, o município é considerado "ente federativo", embora alguns autores, como Castro $(2006,27)$, discordem parcialmente dessa afirmação. Frente ao movimento de descentralização, cabe lembrar, no entanto, que nas décadas de 1970 e $1990^{14}$ o governo federal buscou conter a criação de municípios por inúmeras razões, mas principalmente devido aos gastos com transferências governamentais que daí decorreriam. O governo de FHC, por exemplo, encaminhou a PEC $n^{\circ} 297 / 95$, mas esta foi arquivada.

12 Souza (2004, p. 31) lembra que a Constituição Federal de 1988 já impunha a cada município a elaboração de sua própria Lei Orgânica, mas tal responsabilidade foi acrescida recentemente pela obrigação de formular um Estatuto da Cidade, em função da Lei Federal n. 10 257, de 2001.

13 Órgão previsto na Constituição de 1937 e criado em 1938 com o objetivo de racionalizar a administração pública, rompendo com o que o Estado Novo considerava uma irracionalidade na política.

14 Mas Souza (2002, p. 432) lembra que apenas entre 1988 e 1997 foram criados 1328 novos municípios. 
Almeida (2005) questiona se presenciamos uma recentralização depois do ocorrido na década de 1980, ao argumentar que a luta pela descentralização foi normativa, como resposta "aos 20 anos de autoritarismo burocrático" que a antecedeu. De acordo com a autora, com o movimento de descentralização imaginava-se "[...] que o fortalecimento das instâncias subnacionais, em influenciar os municípios, permitiria aos cidadãos influenciar as decisões e exercer controle sobre os governos locais, reduzindo a burocracia excessiva, o clientelismo e a corrupção" (ALMEIDA, 2005 , p. 29). O apelo pela descentralização foi acolhido mesmo diante da ausência de evidências empíricas, como afirmou Souza (2003b). Mas esse "consenso pela descentralização" sofreu pressões contrárias que, aparentemente, sobrevivem ainda hoje. Embora Almeida (2005) adote o conceito de descentralização firmado pelo Banco Mundial, de acordo com o qual este é apenas a "transferência de autoridade e responsabilidade quanto às funções públicas", ao desenvolver seu argumento afirma a existência de uma complexidade para além dessa definição. Admite, portanto, a premissa de que o federalismo pode ser centralizado ou cooperativo. Segundo a autora, enquanto os Estados Unidos (EUA) vivem um federalismo dual, o Brasil estaria vivendo um regime fiscal dual, pois, como demonstrado por outros autores, a Constituição Federal de 1988 aumentou as transferências da União para os GSN e, ao mesmo tempo, liberou a compensação dos recursos fiscais "perdidos", por meio da arrecadação das contribuições sociais, supostamente com o objetivo de financiar as políticas sociais. Contudo, Almeida considera que a criação de receitas não compartilhadas com os GSN não implica necessariamente um movimento de centralização; tal fato ocorreu quando o Plano Real foi constrangido pela ausência de austeridade fiscal de estados e municípios, o que gerou, por sua vez, forte endividamento público, acusado de ser produto direto da descentralização. Desse modo, o discurso prócentralização presente no período de transição do autoritarismo para a democracia perdeu efeito frente ao discurso da primazia do ajuste fiscal para a estabilização monetária. Esse ambiente político levou a novas rodadas de negociação das dívidas dos estados ${ }^{15}$, privatização dos bancos estaduais

15 A renegociação das dívidas dos estados ocorreu por meio do Projeto Lei n. 9496/97. e à aprovação da Lei de Responsabilidade Fis$\mathrm{cal}^{16}$. Em 1998 programas sociais de transferência de renda foram criados e centralizados pelo governo federal, isto é, "as novas iniciativas dirigidas aos segmentos mergulhados na pobreza extrema re-introduziram a centralização da decisão, recursos e implementação na esfera federal" (idem, p. 38).

Ainda atrelado à discussão das relações intergovernamentais, Arretche e Marques (2002) argumentam que a municipalização é o processo no qual os municípios assumem a administração dos programas sociais e dos centros de decisão, podendo também se responsabilizar pela arrecadação de receita necessária, para tanto. Em outras palavras, municipalização é a formulação e implementação de políticas públicas no plano local, mais especificamente, no âmbito municipal. Os autores argumentam que existe uma lógica inerente às políticas públicas locais, diferenciandoas das demais. Não obstante, paralelo ao fenômeno da municipalização, assistimos ao fortalecimento da autoridade regulatória, a qual é responsável por "[...] planejar, avaliar, auditar, financiar, controlar e, principalmente, punir o mau provedor de serviços" (ARRETCHE \& MARQUES, 2002, p. $60)^{17}$. Por exemplo, no setor de saúde as Normas Operacionais Básicas (NOBs) consolidaram as

16 Para Abrucio (2005, p. 49), a descentralização por repasse de funções e a busca da estabilidade econômica equivaleram, nesse período, à chamada “operação desmonte". Para auxiliar na diminuição do gasto com pessoal nos estados, a União instituiu os Programas de Demissão Voluntária (PDVs), para controlar a folha de pagamentos, financiando as demissões pela Caixa Econômica Federal. Mas o problema novamente residia no pagamento dos inativos. O autor argumenta que os recursos obtidos com as privatizações não deram conta do pagamento da dívida pública devido ao "rombo previdenciário", o que acarretou na criação de leis específicas para impedir a evasão desses recursos, impondo às subunidades o chamado "recolhimento na fonte".

17 Souza (2003b) afirma que, embora os GSN tenham obtido um aumento relativo de suas receitas a partir da Constituição Federal de 1988, a legislação federal não só sobrepõe-se à dos GSN, embora lhes permita ter legislação própria, como também concentra sob sua responsabilidade a formulação de políticas e legislação para as "competências concorrentes". Com a redemocratização, o federalismo passou por um processo de adaptação ao novo formato federativo, seguido pelo Plano Real, que permitiu a noção clara da dívida dos estados e dos grandes municípios, obrigando a União a assumir a resolução desse problema. E, 
regras formais instituídas pelo Ministério da Saúde para determinar o processo de habilitação dos municípios ${ }^{18}$ e houve também uma diferenciação no que tange ao enquadramento dos municípios.

Como vimos, Arretche (1999) mantém uma visão mais tradicional sobre o assunto ao entender a descentralização como transferência de atribuições de gestão do centro, para os GSN. De acordo com a autora, o Sistema Brasileiro de Proteção Social, que inclui educação fundamental, assistência social, saúde, saneamento e habitação popular, sofreu os efeitos da descentralização na década de 1990. Contudo, também para ela, a descentralização não é um processo homogêneo e ocorre de maneira bastante específica em função de cada contexto sócio-histórico. Um elemento novo trazido pela autora diz respeito ao fato de que, a partir do processo de descentralização, surge uma necessidade de que a União promova a adesão dos governos locais à gestão de políticas públicas ${ }^{19}$. Desse modo, não só intervém a cultura local, mas também o histórico com relação a outras políticas, o amparo constitucional, os elementos operacionais das políticas públicas e a própria capacidade fiscal e administrativa. Esses fatores possivelmente são superados pelas chamadas "estratégias de indução". Para a autora, o Brasil antes da redemocratização não se parecia com uma federação, mas com um estado unitário, com centralização política, financeira e administrativa ${ }^{20}$. Todas as políticas do Sistema Brasileiro de Proteção Social eram formuladas, financiadas e implementadas pelo governo federal. Desse modo, embora a descentralização, em tese, beneficie diretamente os GSN para que seja garantida a transferência de atribuições do centro para eles, um

por último, o aumento do controle da gestão dos GSN, contando com escassos mecanismos de cooperação intergovernamental, o que acabou por gerar tensões quanto à distribuição de poder entre os níveis de governo, conquanto no Brasil eles sejam autônomos e interdependentes.

18 O que anteriormente foi tratado aqui, por outros autores, como adesão às políticas públicas formuladas pela União e estados.

19 Para Abrucio (2005) a descentralização também requer a adesão dos GSN às políticas públicas federais, só que tal adesão decorre de processos de coordenação intergovenamental.

20 Ocorre aqui uma confusão entre federalismo e descentralização. conjunto de incentivos deve ser oferecido pelo governo central para estimular a adesão das outras esferas de governo quando não ocorrer obrigatoriedade constitucional para tanto e estiverem presentes as competências comuns ${ }^{21}$. Esses incentivos fazem parte dos programas de descentralização, podendo também antecedê-los, na forma de regulamentação.

\section{CONCLUSÕES}

Os aspectos jurídicos e políticos da descentraliza-ção podem ser observados no que tange às dificuldades de implementação das reformas políticas, nas relações intergovernamentais, nos diversos tipos de descentralização e nas ações regulatórias e fiscalizadoras, que são destacadas neste texto com o intuito de demonstrar o grau de complexidade do processo de descentralização, justificando-se a perspectiva de obrigatório diálogo entre a produção intelectual do Direito e da Ciência Política acerca desse objeto de análise comum. O presente artigo buscou enfatizar que no Brasil pouco se problematizou a relação entre federalismo e descentralização, ao mesmo tempo em que esta foi diretamente associada à autonomização política, fiscal e administrativa dos municípios, inclusive quanto à elaboração, gestão e implementação de políticas públicas.

O ponto de vista jurídico, principalmente o encontrado no Direito Administrativo, preocupase em salientar em que medida a descentralização produz efeitos jurídicos distintos daqueles encontrados em função do processo de desconcentração. Portanto, não dá conta de discutir e problematizar as relações de poder envoltas nesse processo e tampouco se propõe a isso, visto que essa abordagem não é contemplada no escopo da disciplina. Desse modo, cabe à Ciência Política e à Sociologia a função de contrapor à estrutura regulamentária existente os fatos relatados, por si só políticos, sociais e jurídicos, para que se possa discutir efetividade e eficácia; sendo estas fatores fundamentais para o tema em pauta. Essa separação não é problemática e não impede uma colaboração profícua entre as áreas citadas, além de não ferir a autonomia e identidade inerentes a cada área envolvida. Adotar como marco inicial a previsão legal e teórica, nas quais as reformas pautam-se, não permite a discussão da efetividade, apenas

21 Não específicas de um ente apenas. 
relata o que é possível dentro de uma estrutura dada. O dever ser precisa atentar para a realidade concreta, ao mesmo tempo em que esta, para ser compreendida, precisa considerar a operacionalidade e o cotidiano das organizações públicas. A regulamentação é tanto objeto de estudo quanto fonte que auxilia a compreensão de fenômenos diversos, já que a agência humana sofre restrições estruturais. Nesse sentido, reclama-se o relativismo e o relacionismo em análises dessa natureza, com o intuito de promover uma interpretação mais holística da realidade social e política.

Fernanda Henrique Cupertino Alcântara (falcantara@ufv.br) é Doutora em Sociologia pelo Instituto Universitário de Pesquisas do Rio de Janeiro (Iuperj) e Professora na Universidade Federal de Viçosa (UFV).

\section{REFERÊNCIAS BIBLIOGRÁFICAS}

ABRUCIO, F. L. 2005. A coordenação federativa do Brasil: a experiência do período FHC e os desafios do governo Lula. Revista de Sociologia e Política, Curitiba, n. 24, p. 41-67, jun. Disponível em: http://www.scielo.br/pdf/ rsocp/n24/a05n24.pdf. Acesso 4.maio.2011.

ALMEIDA, M. H. T. 2005. Recentralizando a federação? Revista Sociologia e Política, Curitiba, n. 24, p. 29-40, jun. Disponível em: http://www.scielo.br/pdf/rsocp/n24/ a04n24.pdf. Acesso em: 4.maio.2011.

ARRETCHE, M. 1999. Políticas sociais no Brasil: descentralização em um estado federativo. Revista Brasileira de Ciências Sociais, São Paulo, v. 14, n. 40, p. 111-141, jun. Disponível em: http://www.scielo.br/pdf/rbcsoc/ v14n40/1712.pdf. Acesso em: 4.maio.2011.

ARRETCHE, M. \& MARQUES, E. 2002. Municipalização da saúde no Brasil: diferenças regionais, poder do voto e estratégias de governo. Ciência \& Saúde Coletiva, Rio de Janeiro, v. 7, n. 3, p. 455-479. Disponível em: http://www.scielosp.org/pdf/csc/v7n3/ 13025.pdf. Acesso em: 4.maio.2011.

BANDEIRA DE MELLO, C. 2008. Curso de Direito Administrativo. São Paulo: Malheiros.

CASTRO, J. N. 2006. Direito Municipal Positivo. $6^{\text {a }}$. ed. Belo Horizonte: Del Rey.

DIAS, M. 2002. Sob o signo da vontade popular: o orçamento participativo e o dilema da Câmara Municipal de Porto Alegre. Rio de Janeiro: IUPERJ.

FALLETI, T. 2006. Efeitos da descentralização nas relações intergovernamentais: o Brasil em perspectiva comparada. Sociologias, Porto Alegre, v. 8, n. 16, p. 46-85, jul.-dez. Disponível em: http://www.scielo.br/pdf/soc/n16/ a04n16.pdf. Acesso em: 4.maio.2011.

GARSON, S. \& ARAÚJO, E. 2001. Federalismo fiscal: ações sociais básicas - descentralização ou municipalização? Informe-se, Brasília, n. 23, jan. Disponível em: http://www.ici.ufba. br/twiki/bin/viewfile/PROGESP/ItemAcervo 293 rev $=\&$ filename $=$ federalismo_fiscal.pdf. Acesso em: 4.maio.2011.

LIMA, J. C. \& MOURA, M. C. 2005. Trabalho atípico e capital social. Sociedade e Estado, Brasília, v. 20, n. 1, p. 103-133, jun.-abr. Disponível em: http://www.scielo.br/pdf/se/v20n1/ v20n1a06.pdf . Acesso em: 4.maio.2011.

LORDELLO DE MELLO, D. 1971. O município na organização nacional: bases para uma reforma do regime municipal brasileiro. Rio de Janeiro: IBAM.

2004. O município na organização nacional. Rio de Janeiro: IBAM.

LUBAMBO, C. 2006. Desempenho da gestão pública: que variáveis compõem a aprovação popular em pequenos municípios? Sociologias, Porto Alegre, v. 8, n. 16, p. 86-125, jul.dez. Disponível em: http://www.cepam.sp. gov.br/arquivos/artigos/DesempenhodaGestao Publica.pdf. Acesso em: 4.maio.2011.

REZENDE, F. 2003. Modernização tributária e federalismo fiscal. In: REZENDE, F. \& OLIVEIRA, F. A. (orgs.). Descentralização e federalismo fiscal no Brasil. Rio de Janeiro: Konrad. 
REZENDE, F. \& OLIVEIRA, F. A. (orgs.). 2003. Descentralização e federalismo fiscal no Brasil. Rio de Janeiro: Konrad.

RODDEN, J. 2005. Federalismo e descentralização em perspectiva comparada: sobre significados e medidas. Revista de Sociologia e Política, Curitiba, n. 24, p. 9-27, jun. Disponível em: http://www.scielo.br/pdf/ rsocp/n24/a03n24.pdf. Acesso em: 4.maio. 2011.

SARMENTO, D. C. 2005. Criação dos sistemas municipais de ensino. Educação e Sociedade, Campinas, v. 26, n. 93, p. 1363-1390, set.dez. Disponível em: http://www.scielo.br/pdf/ es/v26n93/27285.pdf. Acesso em: 4.maio.2011.

SILVA, M. K. 2006. Sociedade civil e construção democrática: do maniqueísmo essencialista à abordagem relacional. Sociologias, Porto Alegre, v. 8, n. 16, p. 156-179, jul.-dez. Disponível em: http://www.scielo.br/pdf/soc/n16/ a07n16.pdf. Acesso em: 4.maio.2011.

SOUZA, C. 1998. Intermediação de interesses regionais no Brasil: o impacto do federalismo e da descentralização. Dados, Rio de Janeiro, v. 41, n. 3. Disponível em: http://www.scielo. br/scielo.php?pid=S0011-52581998000300003 \&script=sci_arttext. Acesso em: 4.maio.2011.

2001a. Construção e consolidação de instituições democráticas: papel do orçamento participativo. São Paulo em Perspectiva, São Paulo, v. 15, n. 4, p. 84-97. Disponível em: http://www.scielo.br/pdf/spp/v15n4/ 10375.pdf. Acesso em: 4.maio.2011. 2001b. Federalismo e descentralização na Constituição de 1988. Dados, Rio de Janeiro, v. 44, n. 3, p. 513-560. Disponível em: http:// www.scielo.br/pdf/dados/v $44 \mathrm{n} 3 /$ a03v44n3.pdf. Acesso em: 4.maio.2011.

2002. Governos e sociedades locais em contextos de desigualdades e de descentralização. Ciência \& Saúde Coletiva, Rio de Janeiro, v. 7, n. 3, p. 431-442. Disponível em: http://www.scielo.br/pdf/csc/v7n3/ 13023.pdf. Acesso em: 4.maio.2011.

2003a. Federalismo e conflitos distributivos: disputa dos estados por recursos orçamentários federais. Dados, Rio de Janeiro, v. 46, n. 2, p. 345-384. Disponível em: http:// www.scielo.br/pdf/dados/v46n2/ a06v46n2.pdf. Acesso em: 4.maio.2011.

2003b. Regiões metropolitanas: condicionantes do regime político. Lua Nova, São Paulo, n. 59, p. 137-158. Disponível em: http:// www.scielo.br/pdf/ln/n59/a07n59.pdf. Acesso em: 4.maio.2011.

2004. Governos locais e gestão de políticas sociais universais. São Paulo em Perspectiva, São Paulo, v. 18, n. 2, p. 27-41. Disponível em: http://www.scielo.br/pdf/spp/v18n2/ a04v18n2.pdf. Acesso em: 4.maio.2011.

TAVARES BASTOS. 1870 . A província. Rio de Janeiro: MEC.

TORRES, H. G. \& MARQUES, E. 2004. Políticas sociais e território: uma abordagem metropolitana. São Paulo em Perspectiva, São Paulo, v. 18, n. 4, p. 28-38. Disponível em: http://www.scielo.br/pdf/spp/v18n4/ a05v18n4.pdf. Acesso em: 4.maio.2011.

\section{OUTRAFONTE}

Para Controladoria, Conselhos Municipais não têm eficácia. 2006. Jornal do Senado, p. 4, 1824.set. 